\title{
DA VIOLÊNCIA NO COMBATE: \\ O QUE DIZEM OS LUTADORES DE MMA
}

DE LA VIOLENCIA EN EL COMBATE: QUÉ DICEN LOS COMBATIENTES DE MMA

VIOLENCE IN COMBAT: WHAT MMA FIGHTERS SAY

\author{
Cristiano Roque Antunes Barreira ${ }^{1}$
}

${ }^{1}$ Universidade de São Paulo, Ribeirão Preto/SP, Brasil

RESUMO: Cumpre-se uma análise fenomenológica da representação que lutadores(as) de MMA - Mixed Martial Arts têm acerca de seu significado e da violência em sua prática, a partir de suas respostas às perguntas: "Você considera o MMA uma modalidade violenta?" e "O que significa o MMA para você?". Foram entrevistados presencialmente 43 lutadores profissionais, residentes em 8 capitais brasileiras, entre os anos de 2016 e 2017. A análise, baseada no cruzamento intencional, explicita os estratos de base das representações próprias aos sujeitos da prática do MMA, indicando que a perspectiva de um corpo objeto sensível é compatível com a atribuição de violência, mas a perspectiva do corpo sujeito operativo não, possibilitando a compreensão dos significados existencialmente positivos que o MMA tem para eles.

PALAVRAS-CHAVE: Psicologia do esporte; Psicologia fenomenológica; Artes marciais mistas; Combate; Violência.

RESUMEN: Se cumple un análisis fenomenológico de la representación que luchadores de MMA - Mixed Martial Arts - tienen acerca de su significado y de la violencia en su práctica, a partir de respuestas a las preguntas “ ¿Usted considera el MMA una modalidad violenta?” y “Qué significa el MMA para usted?” Entre 2016 y 2017, se entrevistó a un total de 43 luchadores profesionales, que viven en 8 capitales brasileñas. El análisis, basado en el cruce intencional, explicita los estratos de base de las representaciones propias de los sujetos de la práctica del MMA, lo que indica que la perspectiva de un cuerpo objeto sensible es compatible con la atribución de violencia, pero la perspectiva del cuerpo sujeto operativo no lo es, lo que permite la comprensión de los significados existencialmente positivos que el MMA tiene para ellos.

PALABRAS CLAVE: Psicología del deporte; Psicología fenomenológica; Artes marciales mixtas; Combate; Violencia.

ABSTRACT: This paper makes a phenomenological analysis of the representation that MMA - Mixed Martial Arts - fighters have about their meaning and violence in their practice, having as a starting point their answers to the questions: "Do you consider MMA a violent modality?" and "What does MMA mean to you?”. A total of 43 professional fighters, living in 8 Brazilian capitals, were interviewed between 2016 and 2017. The analysis, based on the intentional crossing, explores the basic strata of the MMA practice's own representations, indicating that the perspective of a sensitive object body is compatible with the attribution of violence, but the perspective of the operative subject body is not, which enables the understanding of the existentially positive meanings that MMA has for them.

KEYWORDS: Sport psychology; Phenomenological psychology; Mixed martial arts; Combat; Violence. 


\section{Introdução}

O MMA ou Artes Marciais Mistas é uma modalidade de combate esportivo, nascida oficialmente em 2001, em que dois lutadores combinam técnicas de diferentes artes marciais para efetivar uma disputa corpo a corpo. Nele, a vitória se define pelo nocaute, pelo nocaute técnico (interrupção do juiz), pela submissão (admissão de derrota) de um oponente ou por pontuação (decisão dos juízes). Em meio a intensos debates relacionados à violência que lhe é atribuída, e merecendo atenção de diferentes disciplinas, as últimas duas décadas testemunharam seu grande crescimento mundial, com o número de apreciadores da modalidade estimado em 300 milhões de pessoas (Reinsmith, 2013). Mas se, por um lado, em muitos lugares a resistência ao MMA foi superada, pelo menos do ponto de vista legal e junto a um grande público, por outro lado, as competições de MMA seguem proibidas na França, Noruega e Tailândia. Em 1999, o Conselho Europeu emitiu uma recomendação de proibição dos combates, sob a alegação de que a modalidade atenta contra a dignidade humana. A França acatou a recomendação do Conselho e, vinte anos depois, sua ministra dos Esportes, Roxana Maracineanu, é favorável à regulação e autorização das competições, tendo retomado a discussão sobre o assunto (Paret, 2019).

A questão da violência no MMA tem sido tratada a partir de dois pontos de vista gerais, o dos detratores e o de seus defensores. No MMA, como em outras modalidades que autorizam o contato sem limite de intensidade dos golpes, muitas vezes, não parece haver diferença entre golpear esportivamente e golpear para ferir com hostilidade violenta (Barreira, 2017a). O aspecto fisicamente sensacional desse esporte, acarreta acusações que veem esta como uma prática que lesiona perigosamente os lutadores. Levantamentos que ecoam preocupações médicas têm enumerado os tipos e incidências de lesões decorrentes da prática (Bledsoe, Hsu, Grabowski, Brill, \& Li, 2006; Kochhar, Back, Mann, \& Skinner, 2005; Ngai, Lev, \& Hsu, 2008), evidenciando a face física e mais visível desta modalidade combativa.

Assim como há um debate crítico no âmbito da sociologia do esporte (Sánchez García \& Malcolm, 2010; Van Bottenburg \& Heilbron, 2011), encontram-se, em uma perspectiva de mercado, pesquisas que enfocam o consumo, interessando-se pela motivação dos espectadores de MMA (Cheever, 2009; Lim, Martin, \& Kwak, 2010), e por estratégias de marketing apropriadas para atingir o público consumidor (Andrew, Kim, Greenwell, Lee, \& Mahony, 2008). De modo consequente às preocupações de ordem médica, observa-se a questão em torno do banimento ou não de modalidades extremas de combate (Gauthier, 2009), discussão que na filosofia do esporte aprofunda-se como um reflexo dos argumentos éticos usados por detratores (Dixon, 2016) e defensores (Weimer, 2017) do MMA, havendo em ambos os casos uma perspectiva naturalizada que vê a violência como inerente à prática. Abordagens etnográficas (Downey, 2007; Hirose \& Kei-ho Pih, 2010; Spencer, 2014; Thomazini, Moraes, \& Almeida, 2009) e no campo da psicologia (Vaccaro, Schorock, \& McCabe, 2011; Jensen et al., 2013) têm sido usadas para compreender mais interiormente o fenômeno, embora ignorem ou mencionem apenas marginalmente a questão da violência propriamente dita.

Visto mais de perto, o impacto do fenômeno aguça o interesse acadêmico de antropólogos e psicólogos, o que possibilita apreendê-lo em sua esfera cultural, configurada por seus significados e vivências, conforme a articulação realizada em especial por parte de seus protagonistas (Brent \& Kraska, 2013; Downey, 2007; Spencer, 2014; Thomazini, 
Moraes, \& Almeida, 2009; Williams, 2013). Entre os escassos trabalhos de psicologia sobre o MMA, destacam-se os de Jensen et al. (2013), que fazem uma descrição fenomenológica da experiência típica do lutador de MMA em sua prática de combater, o de Massey et al. (2013), abordando a autorregulação dos praticantes durante a preparação para os combates, e o de Vaccaro et al. (2011), que foca a administração emocional empreendida por lutadores para o enfrentamento de seus adversários.

No campo moral, isto é, no campo dos juízos de valor atribuídos ao MMA, a exemplo dos estudos filosóficos (Dixon, 2016; Weimer, 2017), a violência comparece de modo naturalizado na própria produção do conhecimento científico a respeito. Verificam-se pelo menos três níveis diferentes dessa naturalização da violência: o dos espectadores, o sociológico normativo e o nível experiencial baseado no que os atletas fazem. O perfil dos espectadores de MMA foi verificado por meio de pesquisa online respondida por 2723 pessoas de todo o mundo (Cheever, 2009, p. 32). Entre os motivos que atraem os fãs da modalidade estão "os diferentes estilos que se juntam ( $80 \%$ dos entrevistados) e a competição do esporte (78\%). Os entrevistados também foram atraídos para o MMA porque é preciso mais habilidade do que outros esportes de combate" (Cheever, 2009, p. 36, tradução livre). Aqui a violência está naturalizada como uma das respostas possíveis entre aquelas que indicam o que no MMA atrai os espectadores. No debate sociológico, Sánchez García \& Malcolm (2010) criticam a interpretação de Van Bottenburg e Heilbron (2006) que veem, no incremento de violência dessa modalidade, um processo de des-esportivização. Para os críticos, o aumento da violência seria mais um efeito da impressão provocada pelos combates do que de fatos comprováveis, mas nenhum deles questiona a presença da violência nos combates de MMA, limitando-se apenas a se perguntarem sobre o grau desta violência.

A contextualização e a revisão expostas até aqui exemplificam, principalmente, avaliações referentes à violência "externas" à prática. Entre os trabalhos que fazem uso de abordagens mais internas, em nível experiencial, o assunto "violência” é raramente tematizado, ou pelo menos, raramente tomado como central. Em trabalho etnográfico, Thomazini, Moraes e Almeida (2009) descrevem as experiências corporais que participam da formação identitária de lutadores e lutadoras de MMA, distinguindo as impressões externas do sentido interno da prática, mas também tratando a violência como algo natural e até legítimo no contexto esportivo. A etnografia de Spencer (2014) também toma a violência como fenômeno naturalizado, abordando o aprendizado sensorial pelo que passam os lutadores para lidar com ela. Na discussão das questões de gênero e relações entre as múltiplas masculinidades, Hirose e Kei-ho Pih (2010, p. 198) avaliam que "embora as diferenças culturais sejam facilmente observadas entre os vários mercados regionais, há uma imagem pública bastante coerente de que o MMA é perigoso, violento e, portanto, apenas para 'verdadeiros' homens." Alinhado com as perspectivas internas e as aprofundando, o objetivo deste estudo é analisar fenomenologicamente a representação que os lutadores da modalidade têm acerca da violência em sua prática e do significado do MMA.

\section{Método}

Entre os anos de 2016 e 2017, tendo aprovação pelo Comitê de Ética em Pesquisa, realizou-se um conjunto de entrevistas presenciais com 43 lutadores brasileiros, sendo 9 mulheres e 34 homens, com idades entre 19 e 39 anos, e níveis de experiência que variam 
entre 1 e 14 anos de atuação em eventos oficiais de MMA, registrados no site Sherdog (https://www.sherdog.com/events). A pesquisa se estendeu a 8 capitais, na tentativa de abranger as 5 regiões do país: Rio de Janeiro, São Paulo, Curitiba, Belo Horizonte, Brasília, Salvador, Belém e Manaus. Os entrevistados integravam equipes profissionais, cujos líderes foram responsáveis pela seleção e autorização das entrevistas. Da entrevista semi-estruturada, após transcrição integral, apenas as respostas à duas questões foram analisadas, sendo elas: "Você considera o MMA uma modalidade violenta?" e "O que significa o MMA para você?" A condução das entrevistas ocorreu sob a "escuta suspensiva" (Barreira, $2017 \mathrm{~b}$ ), operando um processo dialógico voltado à compreensão do sentido do que é relatado pelo entrevistado. Já a análise, baseou-se no "cruzamento intencional”, procedimento que, pelo contraste dos sentidos expressos nos relatos, opera diferentes vias de redução, conforme compreensão da fenomenologia clássica de Edmund Husserl e Edith Stein (Barreira, 2017b).

\section{Resultados e discussão}

O problema central enfrentado nesta investigação é a relação entre o lutador de MMA e a violência, a partir de sua visão sobre o esporte que pratica. Como já foi salientado no exame da literatura, quanto mais for visto por fora, mais o MMA é representado como uma disputa naturalmente violenta. Quando a perspectiva de avaliação é interior, a gravidade dessas representações tende a decair. A proposta investigativa considerou a perspectiva interna num registro representativo, partindo das declarações de seus protagonistas. Os resultados estão divididos entre duas visões distintas - as representações que assumem seus combates como violentos e as que recusam essa atribuição defendendo a esportividade da modalidade - cujas análises se aprofundam em elementos experienciais sob a camada representativa dos relatos.

\section{É violento, mas eu gosto}

Questionados se consideram a modalidade violenta, a maioria dos lutadores responde taxativamente que não, o MMA não é violento. A essa resposta se seguem argumentos prontos em defesa da modalidade. Por outro lado, há lutadores profissionais que dizem perceber o MMA como violento. Suas respostas, em grande medida, refletem aquilo que já havia sido encontrado na literatura especializada: "Eu considero [violento] em termos. Eu considero violento por se tratar de uma modalidade de briga, de pancada" (D. A., 33 anos, homem, 14 lutas, Belém, PA). Apresentam-se aí tanto a ênfase no aspecto físico da modalidade como em sua esfera de sentido psicológico, tomando-a como "modalidade de briga”. É, todavia, o aspecto físico que vai ser frisado pelos entrevistados que veem violência no MMA:

Visualmente falando - e mesmo tecnicamente falando - é violência. Se a gente for ver a definição de violência, que é tudo aquilo que contrapõe e te ataca de forma aleatória, se torna violência. De acordo com essa definição de violência, [o MMA] se torna violento. (A. V. A., 28 anos, homem, 3 lutas, Belo Horizonte, MG) 
Neste relato, nota-se como o recurso a uma tentativa de definição objetiva de violência, para o lutador, confirma sua presença. Se a técnica justifica a violência pelo seu efeito físico, o depoente a traz apenas depois daquilo que é visual. Não é sem um forte motivo que, recorrentemente, a visão seja o sentido mais lembrado pelos lutadores que assentem para alguma natureza violenta no MMA. Um trecho de relato demonstra bem como é na percepção visual do confronto que o aspecto violento ganha mais intensidade:

Você sai todo cortado, sangrando, ou o cara sangrando, todo quebrado... É uma coisa que você olha, você fala: 'é bem violento!' A gente que gosta não acha violento, mas, para quem está do lado de fora é violento, é uma briga organizada. (A. W. M., 25 anos, 14 lutas, Belo Horizonte, MG)

Ao listar lesões decorrentes da luta, embora esse seja um relato de alguém que as vive em primeira pessoa, não há menção a qualquer padecimento em virtude da lesão sofrida, mas há quando se analisa como espectador, em terceira pessoa. Em grande parte dos relatos comparece esse contraste entre a perspectiva deles mesmos, lutadores, que gostam de lutar, e a do público, o ponto de vista de quem enxerga de fora, em terceira pessoa. A condição de terceira pessoa é compartilhada pelos lutadores que também assistem às lutas da modalidade, recorrendo naturalmente à consciência de como é ver o combate como espectador. Como no seguinte trecho, em algumas ocasiões eles adotam essa perspectiva de audiência para avaliar o MMA como violento:

Cara... é ... sim! É violento sim. Não vou dizer que não, porque é! Bastante violento sim! É como eu te disse, eu amo o que eu faço, eu gosto de fazer isso. (...) Achar que o esporte é violento, eu acho assim ... eu acho violento em algumas coisas, tipo... quando sangra assim, daí fica uma parada (...) meio que violenta para as pessoas que estão assistindo. Mas eu tenho certeza que quem assiste gosta cara, porque se não gostasse não assistia. E eu acho violento sim. (C. C., 25 anos, homem, 1 luta, Rio de Janeiro, RJ)

Segundo a opinião pessoal deste depoente, a violência no MMA é categoricamente afirmada. Os sangramentos são evocados como momentos expressivos do que há de violento no MMA, aqui não somente aos olhos do público, mas aos olhos do próprio depoente. Entretanto, também se nota como a gravidade da violência - "fica uma parada (...) meio que violenta” - vem matizada pelo contraponto do próprio apreço pela luta. Quando o apreço pelos combates da modalidade é estendido ao público, o contraponto fortalece a resistência perante a ideia de um crivo objetivo e amplamente válido acerca da violência no MMA. Ser ou não violento é, para ele, questão de juízo pessoal.

O contraste entre uma visão de espectador em terceira pessoa, tendendo à objetividade, e uma visão em primeira pessoa por parte dos protagonistas dos combates comparece e é reiterado de diferentes maneiras. Assim, uma lutadora considera que "não é natural (...) você tomar soco, você tomar chute e fingir que nada aconteceu [risos]. Eu acho um pouco violento sim, mas me agrada muito o MMA [risos]” (D. S. B. L., 25 anos, mulher, 2 lutas, Belo Horizonte, MG). Vindo de outra modalidade de combate em que as formas de contato são bem menos extremas e impactantes, o estranhamento desta entrevistada parece ter se modificado apenas pela experiência de competir no MMA: 
Eu sempre achei meio violento, mas até faz bem começar a competir e ver que, tipo, é natural, é instintivo. Eu falo muito para o meu noivo, "putz, é meio que lei da selva [quando] você está lá dentro’. Então, quando eu estou lá acaba não sendo tão violento, acaba sendo natural. É o que eu acho, que acaba sendo natural. (D. S. B. L., 25 anos, mulher, 2 lutas, Belo Horizonte, MG)

Ao mesmo tempo, ainda se nota seu espanto e sua mudança de percepção quando volta à condição de espectadora:

Mas olhando de fora, quando eu assisto a luta de outras pessoas, do próprio UFC, quando eu vou na competição aqui dos meninos, eu falo, 'putz!' Eu vejo o soco, tudo... eu falo, 'nossa!' Mas quando eu estou aqui é natural, eu não sei... [risos]. (D. S. B. L., 25 anos, mulher, 2 lutas, Belo Horizonte, MG)

Entre os lutadores, é comum o entendimento de que "o público vê como violento. É como rinha de galo! Igual você colocar dois animais ali para brigar, todo mundo fica ali torcendo. É a mesma coisa a gente, cara” (H. F., homem, 23 anos, 1 luta, São Paulo, SP). Se esta analogia com a rinha de galos, recorrente entre os detratores da modalidade, poderia sugerir que seus próprios protagonistas reconhecem haver a mais franca violência nesses combates, por outro lado ela é seguida por uma comparação que a assemelha às demais modalidades esportivas:

Estamos ali brigando e o público vem, igual ao futebol! Coloca uma bola lá e depois time briga, um com o outro, para colocar a bola no gol. É a mesma briga, cara! É um querendo ganhar do outro, um time mais que outro, no futebol, no basquete... O esporte é assim,é um querendo ganhar do outro. (H. F., homem, 23 anos, 1 luta, São Paulo, SP)

Perguntada sobre se considera o MMA uma prática violenta, uma das entrevistadas responde que "não tem como dizer que não é!" e complementa "eu acho que é uma violência sadia [risos]” (L. C. S., mulher, 1 luta, Salvador, BA). O paradoxo em se unir sentidos tão contrários como violência e saúde numa mesma sentença leva à pergunta: "Como assim, uma violência sadia?”

Porque... eu não sei explicar... para mim é um jogo de estratégia não é um... eu vejo como jogo de estratégia... não como uma violência, sabe? Mas se você olhar... você vê que é algo violento. Duas pessoas se batendo, não deixa de ser algo violento, não tem como dizer que não é! Eu enxergo como um jogo estratégico. Eu não enxergo violento, enxergo como jogo de estratégia. (L. C. S., mulher, 1 luta, Salvador, BA)

No desenrolar das entrevistas, os lutadores que veem o MMA como violento tendem a nuançar o sentido que a própria violência pode ter. Em alguns casos, ao desenvolverem seus argumentos, rapidamente essa representação cede lugar ao posicionamento contrário, quando a violência passa a ser recusada. Contudo, há da parte deles uma apreensão e compreensão clara daquilo que "naturalmente" motiva a percepção do MMA como sendo violento: ver duas pessoas se ferindo mutuamente e - chegando a sangrar até abundantemente - continuarem se batendo para concluir a luta e vencerem é o que orienta essa percepção. A maioria dos lutadores acessados, contudo, discorda que o MMA seja violento, vendo aí uma posição pautada no desconhecimento acerca da modalidade e da própria vida 
dos lutadores. Perguntado se o MMA é uma modalidade violenta, um profissional afirmou que "de forma física e leiga falando, sim. Quem não entende as regras do esporte, não entende o tanto que a gente treina, considera sim violento" (A. C. P., 35 anos, homem, 5 lutas, Belo Horizonte, MG). Essa posição equivale às que foram expressas por outros profissionais: " $a p a-$ rentemente ele é violento, mas não” (D. H. M., 26 anos, homem, 5 lutas, Belo Horizonte, MG).

Amparando a diferenciação entre aparência e fato, mas de uma perspectiva externa, após analisar 1.270 lutas, Ngai et al. (2008), concluem que "o risco geral de lesão esportiva crítica relacionadas a estas competições parece ser baixo” (p. 686, tradução livre). Chegando a uma conclusão semelhante, Bledsoe e col. (2006) destacam ainda que "as baixas taxas de nocaute no MMA, em comparação com o boxe, podem ajudar a prevenir lesões cerebrais" (p. 186). Estudos comparativos de incidência de lesões mostra que mudanças de regras mais recentes tornam o MMA mais seguro (McClain, Wassarmen, Mayfield, Berry, Grenier \& Suminski, 2014), mas é maior do que nos demais esportes de combate, à exceção do boxe, cujas taxas são similares (Lystad, Gregory, \& Wilson, 2014). Sánchez García e Malcolm (2010), avaliam que o aumento da violência seria mais um efeito da impressão provocada pelos combates do que de fatos comprováveis, relativizando o "grau da violência” e problematizando suas repercussões sociais.

\section{É um esporte de contato, mas não desonesto a ponto de ser violento}

Pode-se dizer que, na perspectiva dos profissionais que recusam que o MMA seja violento, aqueles, lutadores ou não, que o percebem assim estão detidos junto às aparências superficiais do combate. Inicialmente, um fato é determinante para que se possa ir além das aparências, a existência de regras. A modalidade não é violenta, explica uma lutadora, "porque tem as regras e tem um árbitro; se fosse violento, seria na rua" (C. G. C, 31 anos, mulher, 1 luta, Rio de Janeiro, RJ). Seguindo essa direção, mas indispondo-se com relação a certas regras, outra depoente considera que o MMA não é violento: "não... é cheio de regras aí; tem regra até demais, tem que ser mais violento [risos]" (A. T. S. B., 22 anos, mulher, 7 lutas, Salvador, BA). Como ela, outros lutadores consideram que o excesso de regras restringe suas opções combativas. Outros entendem isso como um desenvolvimento da modalidade, lembrando suas origens no chamado Vale-Tudo: "Antigamente poderia até ser [violento], antigamente não tinha regra" (D. H. M., 26 anos, homem, 5 lutas, Belo Horizonte, MG). Com efeito, as mudanças de regulamentação dos combates do tempo do Vale-Tudo ao do MMA são notáveis e continuam a ser revistas. Quando esse argumento aparece em alguns relatos, não há destaque ao modo como essas regras protegem os lutadores de lesões mais perigosas, mas a como elas atendem a uma necessidade de tornar o MMA mais palatável ao público.

Então hoje em dia o esporte está tentando tirar o máximo de lesões possíveis, para tentar ficar uma coisa muito mais bonita, uma coisa mais (...) visivel para quem está vendo e tal. Ele está tentando... colocando o máximo de regras. Algumas regras a gente gosta, outras não. Mas (...) ele não está tão violento igual era, ele está evoluindo. (D. H. M., 26 anos, homem, 5 lutas, Belo Horizonte, MG)

Em todo caso, se a regra é invocada para argumentar que o MMA não é violento ou, ao menos, que não é tão violento como uma briga de rua, também serve a quem, como Dixon (2016), ataque exatamente o que ela permite por considerar que ela autorize a violên- 
cia. A questão se desloca, então, para essas situações que, quando ocorrem sob autorização das regras, levariam à percepção e avaliação de violência no combate. Por isso, "permitir (...) alguns golpes, de repente, ainda torna, para alguma pessoa, violento. Como, sei lá... cotovelada; o cara estar caído e continuar batendo” (E. J. L., 33 anos, homem, 5 lutas, Rio de Janeiro, RJ). As cotoveladas são consideradas pelos lutadores como responsáveis por muitos dos sangramentos nos combates, porque ocasionam cortes com facilidade. Todavia, a rigor o problema não estaria propriamente aí, já que "às vezes, um corte, por exemplo, em uma região que é muito vascularizada, vai sangrar horrores e é um cortinho de nada” (D. H. M., 26 anos, homem, 5 lutas, Belo Horizonte, MG).

Ao discordarem que o MMA seja violento, uma das comparações mais usuais dos lutadores é com o futebol, entre outras modalidades esportivas de contato. Primeiramente, sob a alcunha da violência, a comparação designa o perigo físico: "futebol tem violência ... tem pancada forte... para mim é violento. Então eu não acho o MMA um esporte violento. Ele é um esporte de contato físico" (D. S. S., 25 anos, homem, 1 luta, Rio de Janeiro, RJ). Sublinham como o tipo de contato físico permitido em outras modalidades esportivas abre margens a agressões intencionais por parte dos atletas, estas sim, com um caráter violento que o MMA não teria: "Violentos são os outros esportes que não permitem a porrada e têm a porrada, joelhada, cotovelada... O carrinho que quebra a perna! (...) São porradas desleais, não é para acontecer e acontece" (M. P. A. S. F., 25 anos, homem, 13 lutas, Salvador, BA). Diferentemente, antes de combater no MMA:

Você se prepara para estar ali dentro, não é como o futebol que o cara vem por trás e te dá uma porrada e quebra a sua perna. Você sabe que você vai entrar ali, você tem que se preparar para sair na porrada com o cara! Então eu não considero a modalidade violenta. (M. P. A. S. F., 25 anos, homem, 13 lutas, Salvador, BA)

Entrevistador: O fato de ser porrada não torna violento?

Não, para mim não torna violento. Desde que você saiba que aquilo ali vai ter, eu não acho que é violento. (M. P. A. S. F., 25 anos, homem, 13 lutas, Salvador, BA)

A consciência do que se passa no combate de MMA e a deliberação pessoal de estar lutando são decisivos na avaliação dos lutadores que consideram que esta não é uma modalidade violenta. Para isso, eles alegam que, à diferença do leigo, os praticantes passam por uma preparação que possibilita o enfrentamento físico com um adversário. "Pra mim são dois caras treinados, escolheram estar ali, treinaram, se prepararam” (E. J. L., 33 anos, homem, 5 lutas, Rio de Janeiro, RJ). Esse contexto de preparação para o que será enfrentado dentro do octógono é determinante para o juízo positivo que esses lutadores fazem de sua modalidade:

Você tem técnica, você treina uma disciplina... muitas disciplinas, não uma só... Quando você treina isso, você treina o corpo, treina a mente, é saudável... Você tem que manter uma vida saudável, tem que se manter bem, tem que descansar e treinar. Então eu não acho que isso é uma coisa violenta. Obviamente é um esporte de contato. (C. G. C., 31 anos, mulher, 1 luta, Rio de Janeiro, RJ) 
A preparação a que o atleta se sujeita, bem como, em especial, o fato de que ele tem ciência do que pode se passar com ele e aceita enfrentar um adversário que também tem ciência disso comparece como elemento decisivo de uma percepção que não se prenderia às aparências e impressões de quem julga o MMA violento:

É violento, tipo... ao ver do público. Mas para mim, (...) é tranquilo. Eu gosto do que eu faço, entendeu? Eu amo o que eu faço. Então, não tem porque eu achar violento não. (...) Eu sei que eu estou sujeito a [ser] machucado, a quebrar alguma coisa, a algum corte. Eu sei que eu estou sujeito a isso, mas eu gosto de fazer isso. (C. C, 25 anos, homem, 2 lutas, Rio de Janeiro, RJ)

Esse posicionamento em primeira pessoa, oriundo de quem vivencia o combate, desloca o ponto de vista das representações da violência no MMA. A percepção, então, é a daqueles dois que protagonizam o combate em uma reciprocidade, que não é apenas a do momento imediato em que ele se passa, mas que o antecede dando-lhes condições a ambos de subirem no octógono: "você não entra com uma pessoa despreparada lá dentro, você entra com uma pessoa que é treinada, que é profissional, ela entra ali e sabe o que vai acontecer. Para mim não é violento não” (K. E. M., 27 anos, homem, 11 lutas, Rio de Janeiro, RJ).

Os lutadores de MMA não parecem ignorar o perigo que correm: "eu não posso ser hipócrita e dizer que (...) não é agressivo; é um esporte agressivo, é contundente, você pode machucar feio, como pode não machucar nada” (E. J. L., 33 anos, homem, 5 lutas, Rio de Janeiro, RJ). Ainda assim, parte importante de seus argumentos demonstra que esse perigo, às vezes comparado ao de outros esportes e ocupações profissionais, seria insuficiente para classificar a modalidade como violenta. É na relação entre reciprocidade ou sua ausência, a unilateralidade, que mora a diferenciação essencial e moral de uma argumentação que procura articular a percepção vivida por eles como protagonistas: "eu creio que a violência parte do princípio [de que] está (...) violando a liberdade de outra pessoa” (D. H. M., 26 anos, homem, 5 lutas, Belo Horizonte, MG). Já no combate esportivo, com mais ou menos contato, "quando a questão é consentimento da pessoa, não é violência e tem regra". Afinal, "você está batendo e está tomando, você está batendo e está recebendo” (D. S. S., 25 anos, homem, 1 luta, Rio de Janeiro, RJ). Desse modo, o MMA não se configura como "um esporte injusto, não é uma coisa de uma pessoa só apanhar. É um esporte, é 50\% lá, é 50\% cá” (A. T. S. B, mulher, 22 anos, 7 lutas, Salvador, BA). Mas e quanto ao fato de que as ações de um lutador lesionem o outro? "É esporte de contato, é um esporte de violência, mas não vamos dizer assim desonesto, ao ponto de ser violento. Eu acho justo, um esporte justo.” (A. T. S. B), Nota-se aí que a sombra da violência comparece na terminologia usada para caracterizar a disputa, mesmo quando ela é recusada e o combate é reconhecido como justo. Sob essa sombra, mais uma vez, ainda se contundente e implicando riscos, é a perspectiva em primeira pessoa que desloca a percepção dos praticantes profissionais de MMA como modalidade não violenta e justa:

Para a gente que está lutando não é violento, porque o que eu posso fazer com você, você pode fazer comigo, entendeu? Acho que violência é só uma coisa que eu posso fazer e você não pode fazer, entendeu? (W. M., 25 anos, homem, 14 lutas, Belo Horizonte, MG)

Muito diferentemente, uma situação violenta como uma briga não se submete à reciprocidade: 
Por exemplo, uma briga! O cara dá uma porrada, o outro cai no chão e o cara fica bicando. Eu acho que isso é violento, isso é violento! Você pode matar o cara ali. No MMA você pode tomar um golpe e ser fatal? Pode, é o risco. Como um cara que vai pintar o prédio e pode cair. (...) Não é um negócio, assim, que o cara vai ficar batendo até você morrer, sabe? (A. B., 23 anos, homem, 4 lutas, São Paulo, SP)

Outro entrevistado ilustra com cores mais fortes como enxerga o fenômeno da agressão violenta:

Violento é bater na mulher, violento é bater no filho, violento é estupro, violento é a polícia (...). Eu acredito que o MMA é extremo, é intenso. É um esporte extremo, mas (...) é uma marcação de pontos (...). O cara que bate na mulher na frente dos filhos - esse cara é violento! (T. A. V., 26 anos, homem, 12 lutas, São Paulo, SP)

O mesmo lutador avalia ainda:

Agora, eu que aceito lutar com um cara que também aceita lutar comigo, por uma quantia de dinheiro e por um entretenimento ao público: isso não é violento, isso não é violento. (...) Isso é saudável! Isso é bom! Eu vou ganhar dinheiro, você vai assistir, você vai gostar. Agora o esporte em si, ele é extremo, ele é difícil, ele é um esporte extremo, intenso, mas violento não. Essa é a minha consideração. (T. A. V., 26 anos, homem, 12 lutas, São Paulo, SP)

Isso significa que, segundo esses lutadores, não haja violência no MMA? Não, significa apenas que eles não consideram que o MMA tenha uma qualidade violenta, isto é, que o MMA seja naturalmente violento. Em certas ocasiões eles enxergam a violência acontecendo. Um lutador e técnico da modalidade, o considera violento quando gerenciado por maus profissionais, "que colocam certos tipos de alunos para lutar quando não têm condições ainda” (R. A. M. C., 39 anos, homem, 20 lutas, Salvador, BA).

Entrevistador: Que condições?

Físicas, psicológicas, técnicas. MMA não é uma rinha de galo, [em que] você solta e ele faz. Eu vejo muitos alunos aí com menos de um ano e os professores colocando no MMA. Isso é uma coisa que deveria ser banida, professores assim, técnicos assim ou árbitros assim, como queira chamar. Eu acho que o MMA ainda precisa, nesse ponto, melhorar muito. (R. A. M. C., 39 anos, homem, 20 lutas, Salvador, BA)

Entrevistador: $O$ que faz com que esses lutadores com pouco preparo, pouco tempo, façam o MMA ser violento?

Porque acaba botando, vamos dizer... um com técnica... agressividade, psicológico bom... com um cara que não tem nada. Aí fica muito fácil! É como você pegar um Boby-aquele boneco que tem no boxe - e você bater em um Boby. É um só batendo e o outro apanhando. (R. A. M. C., 39 anos, homem, 20 lutas, Salvador, BA). 
A considerar pelos lutadores que não entendem o MMA como uma modalidade violenta, portanto, existem condições necessárias para que, nessa disputa de contato físico, haja justiça. Esta não extrai do combate a agressividade e as injúrias físicas, mas equivale a fazê-lo uma "luta honesta" e, como tal, segundo eles, uma disputa não violenta. Essas condições, fundamentalmente, são aquelas que garantem reciprocidade combativa, sua natureza envolve necessariamente o mútuo enfretamento, o bater com, inerente à sua etimologia. Isso significa, mostra a análise fenomenológica, que não existe combate físico unilateral. Sem haver reação e resposta, sai o combate de cena para a entrada do espancamento (Barreira, 2017c).

\section{O que significa o MMA para você?}

Ao responder a essa pergunta, os lutadores profissionais entrevistados relatam um tal envolvimento e transformação pessoal com a modalidade que muitos deles tratam o que vivem no MMA como uma espécie de conversão existencial: "o MMA mudou a minha vida" e "o MMA é a minha vida" são as respostas mais frequentes. O "MMA é minha vida, é meu cotidiano, é minha rotina, é meu prazer, é ... minha tristeza também (...). É minha dificuldade, é a minha guerra, é ... é minha vida. (T. A. V., 26 anos, homem, 12 lutas, São Paulo, SP)

É importante ter em consideração que, a exemplo da vida de profissional em outras modalidades esportivas de alto rendimento, o comprometimento e as exigências para haver algum sucesso demandam rotinas planejadas quase inteiramente em virtude dos treinamentos e competições. Portanto, relatos como esses estão longe de ser exclusividade desta modalidade: "Uma profissão, um esporte assim, qualidade de vida... qualidade de vida não é né! (...) Não vou mentir! [risos] Eu acho que qualquer atleta de alto rendimento não tem qualidade de vida, né!” (A. B., 23 anos, homem, 4 lutas, São Paulo, SP).

É interessante, porém, apreender como as vivências intencionais do autodesafio, com todas as suas ressonâncias como reconhecimento social e estima pessoal (Honneth, 2003), se afastam de qualquer sentido de violência e designam o sentido de dignidade que o combate de MMA tem para seus profissionais.

O MMA é minha vida. Eu vivo por isso aqui, eu amo estar aqui dentro, eu amo... eu amo tudo. Eu amo a emoção, eu amo o jeito de lutar, o jeito que as pessoas reagem à gente, eu amo as criancinhas que gostam de mim. Eu acho bem legal essas coisas. O MMA, tipo, conseguiu me tirar das drogas, e me mostrar para as pessoas, para ser um exemplo, sabe? Não tem preço isso. É tudo para mim, não tem muito o que falar, o MMA para mim é tudo. (H. F., 23 anos, homem, 1 luta, São Paulo, SP)

Alguns lutadores e lutadoras enxergam o MMA como um esporte que os resgatou de vidas problemáticas, da violência da "vida real", com suas disfunções familiares, injustiças sociais e escassez material, casos em que a dignidade da luta parece se confundir com a dignidade da vida, além da opção profissional que ela representa: "o MMA para mim é tudo, respeito... responsabilidade... tudo... tudo... tudo você aprende no MMA, aprende a ser profissional, tudo, no MMA você aprende muita coisa, você passa por muita coisa, é isso." (A., mulher, 21 anos, 7 lutas, Salvador, BA). 
A longa distância que separa de um lado o senso comum e acadêmico de uma violência inerente ao MMA e, de outro, o senso de dignidade que é atribuído e vivido pelos lutadores entrevistados, pode ser reconduzida, ainda que não inteiramente reduzida, à estrutura vivencial que veio se anunciando, ao longo desses resultados, como diferente entre as posições de terceira e primeira pessoas.

\section{Da representação à estrutura vivencial}

Levantados os argumentos dos lutadores quando veem e quando não veem violência no MMA, bem como o significado da modalidade para eles, é possível agora penetrar naquilo que eles dizem para colher elementos inalienáveis que estruturam vivencialmente seus pontos de vista. A primeira característica que emerge na percepção de violência inerente ao MMA é que ela se coloca eminentemente sob o ponto de vista do espectador. Para os lutadores, a violência é afirmada por aquilo que se vê acontecer em uma luta testemunhada, nunca numa luta protagonizada por eles. O que eles mesmos padecem e fazem não é recuperado em suas percepções e argumentos para justificar a atribuição de violência ao MMA. Trata-se, então, de notar na corporeidade alheia os efeitos das ações combativas. O mais aparente e imediatamente lembrado é o das lesões, especialmente com cortes e sangramentos. A isso se segue o da condição e vulnerabilidade do lutador no perigo de ser golpeado e não poder mais se defender e agir, condição limítrofe em que se transita à perda de reciprocidade combativa e ao espancamento, quando, pelas normas, a luta deve ser interrompida. Nessa série perceptiva é, primeiramente, a faceta física, seguida pela sensível, aquela que predomina e persiste como percepção de violência junto ao corpo objeto e sensível. Trata-se de notar o corpo que padece. Sua condição de padecimento se intensifica pelo apagamento operativo do corpo.

Ao contrário, em primeira pessoa, a corporeidade é, antes de mais nada, vivida como ação, positivamente invisibilizada por um desaparecimento ou quase desaparecimento da esfera do corpo sensível. É isso que comparece quando os lutadores referem que combater é instintivo, estratégico, fonte de gosto e amor, mas também honesto e justo, por isso dizem viverem a luta, amarem sua emoção e o que fazem no octógono e nos treinamentos. Dessa posição em primeira pessoa, sobressai-se a operatividade do corpo próprio, condição de sujeito da ação que, mesmo se sujeito à ação do oponente, segue ativo na luta, defendendo-se e atacando. Essa é a posição privilegiada da recusa a um sentido violento inerente ao MMA.

Em análises fenomenológicas anteriores, relativas ao fenômeno da violência no esporte, chegou-se à definição de um conceito operacional para abordar a questão na esfera do corpo a corpo esportivo. Trata-se da norma de sensibilidade, acordo tácito, sensível, implícito à interação entre sujeitos e, no interior de determinados limites, largamente passível de modulação (Barreira, 2017a). Esta norma vigora num território de intersecção entre a objetividade e a subjetividade, contemplando critérios normativos objetivos e as vivências subjetivas de quem se instala afetado por esse horizonte normativo, como é o caso das regras esportivas do MMA. Segundo esse critério, nem uma ação nem uma consequência objetiva dela, como uma lesão, são por si só suficientes para caracterizar a violência. A passagem à violência se dá no momento em que, seja qual for o parâmetro de agressividade usado, haja o desbotamento do outro numa ação que o coisifica agressivamente (Barreira, 2017a). Posto isso, pode-se compreender como, para quem está posicionado em terceira 
pessoa, vendo as consequências físicas de um corpo golpeado e apreendendo empaticamente seu padecimento, a fronteira do que lhe aparece como aceitável é atingida, rompendo os índices liminares para suas zonas de normalidade sensível (Barreira, 2017a).

No posicionamento em primeira pessoa, o padecimento sensível comparece menos do que a operatividade ativa do lutador, pela qual o limiar da sua norma sensível encontra outros parâmetros de referência, fazendo o combate ser percebido como não violento.

\section{Considerações finais}

Em linhas gerais, apresentam-se as considerações que os lutadores profissionais fazem em relação à violência e à não violência da modalidade de combate que praticam. Ver violência no MMA é compatível com a percepção em terceira pessoa e com outras considerações de ordem objetiva (especialmente médicas), todas atinentes ao respeito ao corpo objeto sensível. Sob o ponto de vista objetivo, o MMA pode ser entendido como violento, assumindo-se a violência como o inaceitável no esporte. Todavia, a objetividade não consiste no todo da percepção sequer dos lutadores que veem a "violência", uma vez que está matizada pelo seu gosto pela modalidade, o que torna aceitável aquilo que poderia ser inaceitável sob um olhar exclusivamente exterior; portanto, nestes termos, o MMA não é violento. Nada disso afasta a possibilidade de surgimento da violência, o que pode ocorrer, por exemplo, quando técnicos irresponsáveis colocam lutadores despreparados para competir, ou quando há falta de técnica e autocontrole. Experiências de violência vividas por lutadores de MMA serão tematizadas em outro trabalho.

Não ver violência no MMA, por sua vez, equivale a uma apreensão empática rente à percepção da perspectiva, não do corpo sensível, mas do corpo sujeito operativo e ao entusiasmo combativo dos lutadores, empenhados de modo determinado em fazer seu melhor na disputa corporal e existencial que encaram. Os lutadores se apoiam, nas suas respostas, no deslocamento do ponto de vista de terceira para primeira pessoa, na superação do enfoque sensacional no aspecto físico da luta com sua aparente violência, na existência de regras, na comparação com outros esportes, na consciência do perigo, na igualdade de condições entre os combatentes e na justiça na luta. Para eles não há violência dentro do octógono quando os participantes estão identificados com essas colocações.

Seguindo esse raciocínio, bem entendido, embora as lacerações possam impressionar e contrariar uma parte do público, a percepção de violência não estaria nos sangramentos, mas no perigo de certos golpes aplicados em condições de vulnerabilidade do oponente. E isso só seria possível em situações de desrespeito às regras, descontrole emocional ou deficiência técnica de um ou ambos os competidores, bem como por falha da arbitragem. Trata-se propriamente de um problema, uma vez que a percepção e avaliação quanto a isso variam elasticamente, tanto no que se refere à sensibilidade de quem assiste e de quem luta como aos critérios de arbitragem para se determinar aquilo que é ou não perigoso, assunto próprio à intersecção objetividade-subjetividade das normas sensíveis (Barreira, 2017a).

A estrutura vivencial, a que se chegou com amparo do material empírico, é restrita por seu conteúdo representativo, limitando o presente estudo. Como hipótese analítica, o cruzamento intencional dos relatos de experiência vivida em primeira pessoa, conteúdos não representativos, mas experienciais, poderá resultar em constatação empiricamente mais sustentável da análise aqui iniciada. 


\section{Referências}

Andrew, D. P. S., Kim, S., Greenwell, T. C., Lee, J., \& Mahony, D. F. (2008). An Analysis of Spectator Motives in an Individual Combat Sport: A Study of Mixed Martial Arts Fans. Sport Marketing Quarterly, 17, 109-119.

Barreira, C. R. A. (2017a). A norma sensível à prova da violência: o corpo a corpo em disputa sob a ótica fenomenológica em Psicologia do Esporte. Phenomenological Studies: Revista da abordagem gestáltica, XXII, 278-292.

Barreira, C. R. A. (2017b). Análise fenomenológica aplicada à Psicologia: recursos operacionais para a pesquisa empírica. In M. Mahfoud \& J. Savian (Orgs.), Diálogos com Edith Stein (pp. 317-368). São Paulo: Paulus.

Barreira, C.R.A. (2017c). The essences of martial arts and corporal fighting: a classical phenomenological analysis. Archives of Budo, 13, 351-376.

Bledsoe, G. H., Hsu, E. B., Grabowski, J. G., Brill, J. D., \& Li, G. (2006). Incidence of injury in professional mixed martial arts competitions. Journal of Sports Science and Medicine, Combat Sport (Special Issue), 136-142.

Brent, J. J. \& Kraska, P. B. (2013). 'Fighting is the most real and honest thing': Violence and the Civilization/Barbarism Dialectic. Brit. J. Criminol. 53(3), 357-377.

Cheever, N. (2009). The uses and gratifications of viewing mixed martial arts. Journal of Sport Media, 4(1), 25-53.

Dixon, N. (2016). Internalism and external moral evaluation of violent sport. Journal of the Philosophy of Sport, 43(1), 101-113.

Downey, G. (2007). Producing Pain: Techniques and Technologies in No-holds-barred Fighting. Social Studies of Science, 37(2), 201-226.

Gauthier, J. (2009). Ethical and Social Issues in Combat Sports: Should Combat Sports Be Banned? In R. Kordi, N. Maffulli, R. R. Wroble, \& Wallace, W. A. (Orgs.), Combat Sports Medicine (pp. 73-88). Londres: Springer-Verlag.

Hirrose, A. \& Kei-Ho Pih, K. (2010). Men Who Strike and Men Who Submit: Hegemonic and Marginalized Masculinities in Mixed Martial Arts. Men and Masculinities, 13(2), 190-209.

Honneth, A. (2003). Luta por reconhecimento: a gramática moral dos conflitos sociais. (L. Repa, Trad.). São Paulo: 34. (Original em alemão publicado em 1992).

Jensen, P., Roman, J., Shaft, B., \& Wrisberg, C. (2013). In the Cage: MMA Fighters' Experience of Competition. The Sport Psychologist, 27, 1-12.

Kochhar, T., Back, D. L., Mann, B., \& Skinner, J. (2005). Risk of cervical injuries in mixed martial arts. British Journal Sports Medicine, 39(7), 444-447.

Lim, C. H., Martin, T. G., \& Kwak, D. H. (2010). Examining Television Consumers of Mixed Martial Arts: The Relationship Among Risk Taking, Emotion, Attitude, and Actual Sport-Media-Consumption Behavior. International Journal of Sport Communication, 3(1), 49-63.

Lystad, R. P., Gregory, K., \& Wilson, J. (2014). The Epidemiology of Injuries in Mixed Martial Arts: A Systematic Review and Meta-analysis. Orthopaedic Journal of Sports Medicine, 2(1). https://doi.org/10.1177/2325967113518492

Massey, W. V., Meyer, B. B., \& Naylor, A. H. (2013). Toward a grounded theory of self-regulation in mixed martial arts. Psychology of Sport and Exercise, 14(1), 12-20.

McClain, R., Wassarmen, J., Mayfield, C., Berry, A. C., Grenier, G., \& Suminski, R. R. (2014). Injury Profile of Mixed Martial Arts Competitors. Clinical Journal of Sport Medicine, 24(6), 497-501.

Ngai, K. M., Levy, F., \& Hsu, E. B. (2008). Injury trends in sanctioned mixed martial arts competition: a 5-year review from 2002 to 2007. British Journal Sports Medicine, 42(8), 686-689. 
Paret, G. (2019). MMA: la France entre dans la cage! Le Point.fr. Recuperado de https://www. lepoint.fr/sport/mma-la-france-entre-dans-la-cage-04-04-2019-2305800 26.php\#

Reinsmith, T.(2013). Worldwide, MMA is bigger than MLB, and a look at Ronda Rousey's superstar status. Bloody Elbow. Recuperado de http:/www.bloodyelbow.com/2013/10/15/4841272/ ufc-mma-bigger-mlb-ronda-rousey-superstar-andersonsilva-georges-st-pierre-jon-jones

Sánchez García, R. \& Malcolm, D. (2010). Decivilizing, civilizing or informalizing? The international development of Mixed Martial Arts. International Review of the Sociology of Sport, 45(39), 39-58.

Spencer, D. C. (2014). Sensing violence: An ethnography of mixed martial arts. Ethnography, $15(2), 232-254$.

Thomazini, S. O., Moraes, C. E. A., \& Almeida, F. Q. (2009). Controle de si, dor e representação feminina entre lutadores(as) de mixed martial arts. Pensar a Prática, 11(3), 281-290. Vaccaro, C. A., Schorock, D. P., \& McCabe, J. M. (2011). Managing emotional manhood: fighting and fostering fear in Mixed Martial Arts. Social Psychology Quarterly, 74(4), 414-437. Van Bottenburg, M. \& Heillbron, J. (2011). Informalization or de-sportization of fighting contests? A rejoinder to Raúl Sánchez García and Dominic Malcolm. International Review for the Sociology of Sport, 46(1), 125-127.

Weimer, S. (2017). On the alleged intrinsic immorality of mixed martial arts. Journal of the Philosophy of Sport, 44(2), 258-275.

Williams, R. (2013). Études de causes sociales et biologiques de la violence dans le contexte des artes martiaux mixtes. In F. Heuser, A. Touboul, \& A. Terrisse (Org.). Éthique, Sports de Combat \& Arts Martiaux (pp. 321-331). Toulouse, FR: Presses de l'Université Toulouse.

\section{CRISTIANO ROQUE ANTUNES BARREIRA \\ http://orcid.org/0000-0003-0141-6828}

Psicólogo e professor, com doutorado em Psicologia pela Faculdade de Filosofia Ciências e Letras de Ribeirão Preto/USP (2004). De 2005 a 2009, foi professor junto à Escola de Artes Ciências e Humanidades (USP). Atualmente é Diretor da EEFERP/USP (desde 08/2017) e Presidente da ABRAPESP (desde 11/2017). Também é professor associado (RDIDP) na Escola de Educação Física e Esporte de Ribeirão Preto/USP, e professor orientador no Programa de pós-graduação em Psicologia/FFCLRP/USP.

ENIDEREÇO: Av. Bandeirantes, 3900, Ribeirão Preto/SP. CEP 14030-680.

E-MAIL: crisroba@gmail.com

\begin{tabular}{ll} 
Histórico & $\begin{array}{l}\text { Submissão: 28/12/2018 } \\
\text { Revisão:25/04/2019 } \\
\text { Aceite:23/05/2019 }\end{array}$ \\
\hline $\begin{array}{l}\text { Financiamento } \\
\begin{array}{l}\text { Consentimento de } \\
\text { uso de imagemo de Amparo à Pesquisa do Estado de São Paulo - FAPESP, } \\
\text { projeto: 20129-0 }\end{array}\end{array}$ & Não se aplica \\
\hline
\end{tabular}

